\title{
Gap Junctions in Development and Disease Elke Winterhager, ed
}

\author{
Springer Verlag 2005; 279 p. Hardcover; $€$ 129.25, L 100, sFr 220, \$ 169
}

\author{
Hans Bloemendal
}

Received: 29 August 2006/Accepted: 5 September 2006/Published online: 8 June 2007

(C) Springer Science+Business Media B.V. 2007

This is a valuable book for those scientists who are interested or are involved in the study of cell membranes in general and particularly in the structure and function of gap junctions.

Cell junctions are formed by interaction of two eukaryotic cell membranes. A special category of such junctions, is named gap junctions that are communicating junctions between two cells mediating the passage of small molecules. The term gap junction is derived from the notion that they act as transmembrane channels (connexons) whereby the interacting plasma membranes are separated by a gap of about $3 \mathrm{~nm}$. The function of gap junctions is dealt with in this book entitled Gap Junctions in Development and Disease (edited by Elke Winterhager). In 12 chapters contributed by different authors, including the editor, a variety of aspects is described in a concise and clear manner. Recent insight into the role of the different connexin genes and their expression products may deepen our understanding of the action of connexons. In this respect the use of connexin knock out mice appeared to be a powerful tool. A striking result of such an experimental approach was the discovery of a special heart defect. Another fruitful experimental device was the replacement of a particular connexin by another isoform. The crucial part played by the gap junctions has been demonstrated in the process of development and skeletal muscle regeneration.Other amazing findings were the discovery that mutations of connexins might be responsible for heriditary deafness and cataract.
All the underlying data can be found in the following chapters:

1) Connexin and Pannexin in te Mouse and Human Genome

2) Essential Role of Gap Junctions during Development and Regeneration of Skeletal Muscle

3) Connexins in Cardiac Development Expression, Role and Transcriptional Control

4) Gap Junction and Connexin Remodeling in Human Heart Disease

5) Gap Junction Expression in Brain Tissues with Focus on Development

6) Connexins Responsible for Hereditary Deafness

7) Human Connexins in Skin Development and Skin Disorders

8) Intercellilar Communication in Lens Development and Disease

9) Connexin Modulators of Endocrine Function

10) Roles of Gap Junctions in Ovarian Fulliculogenesis Implications for Female Invertility

11) Placental Connexins of Mice and Man

12) Connexins in Growth Control and Cancer

H. Bloemendal ( $\square)$

Radboud Universiteit Nijmegen, 271 Biomoleculaire Chemie,

NCMLS (Researchtoren), Geert Grooteplein 26-28, Postbus

9101, NL-6500 HB Nijmegen, The Netherlands

e-mail: h.bloemendal@NCMLS.RU.nl

Hans Bloemendal 